\title{
Gender differences among adolescent gamblers
}

\author{
S. Weidberg*, A. González-Roz, J.R. Fernández-Hermida, V. Martínez-Loredo, \\ A. Grande-Gosende, Á. García-Pérez, R. Secades-Villa \\ Addictive Behaviors Research Group, Department of Psychology, University of Oviedo, Plaza Feijóo s/n, 33003 Oviedo, Spain
}

\section{A R T I C L E I N F O}

\section{Keywords:}

Gambling severity

Adolescents

Gender

Risk factors

\begin{abstract}
A B S T R A C T
Gambling has been considered a male pastime with research focused on exploring risk factors for gambling without considering gender differences. Despite gambling has greatly increased among women in recent years, few studies have explored gender differences in adolescent gamblers. This study analyzed gender differences in risk factors and gambling-related patterns. The sample comprised 1756 adolescents aged 14 to 17 years. Chisquare and $t$-tests were performed to examine differences between male and female gamblers $(n=699)$. Multiple regressions were conducted to explore predictors of gambling severity by gender. Male gamblers reported more gambling activity within the last year and showed a more severe gambling pattern. Impulsivity, last year prevalence of bingo, and other casino games were associated with higher gambling severity in both genders. Enhancement and coping motives were related to gambling severity only in males, while mixed-mode gambling was related to gambling severity in females. Our findings extend the research on gender differences among adolescent gamblers by showing that gender specific risk factors exist and should be regarded by health providers when designing treatment strategies.
\end{abstract}

\section{Introduction}

Problem gambling is defined as a recurrent behavior characterized by loss of control and excessive preoccupation with gambling, that leads to a significant impairment in occupational and social life areas (American Psychiatric Association, 2013). The prevalence of problem gambling among adolescent males is more than two times higher than in females (Edgren, Castren, Jokela, \& Salonen, 2016). Due to the range of sociodemographic (e.g., low educational level), biological (e.g., low serotonin levels) and psychosocial (e.g., high impulsivity) variables proposed as risk factors for gambling initiation (Blaszczynski \& Nower, 2002; Castrén et al., 2013; Pérez Fuentes, Molero Jurado, Carrión Martínez, Mercader Rubio, \& Gázquez, 2016; Topf, Yip, \& Potenza, 2009), current models of addiction conceptualize gambling within a biopsychosocial perspective (Griffiths, 2005). Accordingly, the differential impact of these variables might explain gender differences in problem gambling rates.

Despite the increasing number of studies exploring gambling prevalence among adolescents (Calado, Alexandre, \& Griffiths, 2017), gender differences have been largely unexplored, and studies have yielded mixed results. Kaminer, Burleson, and Jadamec (2002) found that although males experience more gambling problems, females display a younger age of gambling onset. While Stinchfield (2000) found that more males reported gambling on the lottery and in casinos than females, Desai, Maciejewski, Pantalon, and Potenza (2005) showed no differences in the prevalence of casino and non-casino games by gender.

Potential factors underlying gender differences in gambling exist. Focusing on psychological factors, research on adult gamblers highlights that motives for gambling differ by gender. Females typically report gambling for managing dysphoria/depression, while males engage in gambling as a way of attaining self-enhancement (Petry, Stinson, \& Grant, 2005; Stewart \& Zack, 2008). Mixed results exist regarding impulsivity among problem gamblers, with some studies finding a stronger association in males (González-Ortega, Echeburúa, Corral, Polo-López, \& Alberich, 2013) and others in females (Nigro, Cosenza, \& Ciccarelli, 2017). From the social environment perspective, perception of economic profitability, and peer and parental gambling behavior differentially affect gambling by gender (Donati, Chiesi, \& Primi, 2013). Lastly, testosterone levels have been shown to increase risk-taking decisions (Stanton, Liening, \& Schultheiss, 2011), especially in females (Sapienza, Zingales, \& Maestripieri, 2009). It is possible that this testosterone sensitivity leads to different gambling involvement in both sexes.

Other socio-environmental factors such as the educational level or the mode of gambling access (i.e., land-based, online, mixed-mode) have been largely unexplored in adolescents. As mixed-mode gambling

\footnotetext{
* Corresponding author at: Department of Psychology, University of Oviedo, Plaza Feijóo, s/n, 33003 Oviedo, Spain.

E-mail address: weidbergsara.uo@uniovi.es (S. Weidberg).
} 
is associated with the presence of gambling related problems (GonzálezRoz, Fernández-Hermida, Weidberg, Martínez-Loredo, \& Secades-Villa, 2016), it is important to consider the impact of specific modes of access separately by gender.

This paper explores gender differences among adolescent gamblers. The specific objectives were: 1) to estimate gender differences in gambling prevalence among adolescents; 2) to explore gender differences in gambling patterns; and 3) to identify risk factors for gambling separately by gender.

\section{Material and methods}

\subsection{Participants}

Participants were adolescents aged $14-17$ years $(M=15.22$, $S D=0.74)$. The initial sample size was made up of 1810 participants from 22 Spanish secondary schools in Asturias and Alicante (Spain). Recruitment was done between October 2015 and May 2016. Inclusion criteria were: 1 ) being aged $<18$ years; 2 ) having no sensory impairment; 3) not presenting difficulties in understanding the Spanish language; and 4) not being diagnosed with an intellectual disability. Two participants were discarded due to intellectual disabilities and 9 because they were 18 years old. In accordance with the instructions of the Oviedo Infrequency Scale (Fonseca-Pedrero, Paino, Lemos-Giráldez, \& Muñiz, 2008), 43 surveys with more than three erroneous responses were discarded from subsequent analyses. Thus, 1756 participants (53.6\% males) comprised the final sample. Of them, 39.8\% $(n=699$, 437 males and 262 females) had gambled within the last year (see Table 1 for descriptive statistics). Power analyses were computed using GPower* and the guidelines posed by Mayr, Erdfelder, Buchner, and Faul (2007). A minimum sample size of 250 participants indicated an adequate statistical power for bivariate $(98 \%$ power for Chi-Squared and $100 \%$ for $t$-tests, $\alpha=0.05$, two-sided) and regression analyses (83\% power to detect an odd ratio of 1.6 , two-tails). The inclusion of a sample size larger than the one previously indicated guaranteed sufficient power.

\subsection{Procedure}

Schools were selected following a random stratified and incidental procedure and the study was approved by the Ethics Committee of the Spanish Education Ministry.

Students completed an anonymous questionnaire using electronic tablets (Samsung Galaxy Tab2 10.1 tablet). Trained supervisors checked that they were doing the task appropriately.

\subsection{Measures}

Data regarding age, sex and family structure (i.e., living with no parents or with one or two parents) were collected. Participants were asked about their most frequent academic mark obtained in the last semester. This variable took the following values: outstanding (A and $A+$ ), notable (from $B-$ to $B+$ ), good (from $C-$ to $C+$ ) and failing (from $\mathrm{F}$ to $\mathrm{D}+$ ). We also asked for the amount of weekly allowance. This variable took the following values: $0 €-20 €(\$ 22.4) ; 21 €-40 €$ (\$23.5-\$44.8); $\geq 41 €(\$ 45.9)$. The presence of participants' problematic gambling relatives was also assessed.

The Oviedo Infrequency Scale (Fonseca-Pedrero et al., 2008) was used for detecting random responses.

An ad-hoc survey assessed gambling engagement. We collected data on: mode of access, gambling activities engaged in within the last year, time and money spent per gambling occasion, age at gambling onset, last year's gambling involvement (defined as the number of games that participants engaged in over the last semester) and number of games in their first year of gambling. Gambling venues such as exclusively land based, online, or mixed-modes of access, and a set of gambling activities were evaluated. Given the low prevalence of online gambling $(n=17)$, this mode of access was not included in subsequent analyses. A landbased venue was defined as gambling in the last year through a terrestrial mode of access, exclusively. Mixed-mode access was defined as gambling in both land-based and online contexts (that is, gambling both online and offline in the same activity). Specifically, last year prevalence of bingo, poker, other casino games (OCGs), sports betting, lottery, scratch-tickets and electronic gambling machines (EGMs) was measured as a function of the above gambling modes.

Table 1

Sociodemographic characteristics of the final sample $(N=1756$, left panel) and subsample of gamblers $(n=699$, right panel).

\begin{tabular}{|c|c|c|c|c|c|c|c|c|c|c|c|c|c|c|}
\hline & \multicolumn{2}{|c|}{ Females $(n=814)$} & \multicolumn{2}{|c|}{ Males $(n=942)$} & \multirow[t]{2}{*}{$\chi^{2}$} & \multirow[t]{2}{*}{$p$} & \multirow[t]{2}{*}{ Cramer's V } & \multicolumn{2}{|c|}{$\begin{array}{l}\text { Female gamblers } \\
(n=262)\end{array}$} & \multicolumn{2}{|c|}{$\begin{array}{l}\text { Male gamblers } \\
(n=437)\end{array}$} & \multirow[t]{2}{*}{$\chi^{2}$} & \multirow[t]{2}{*}{$p$} & \multirow[t]{2}{*}{ Cramer's V } \\
\hline & $\mathrm{n}$ & $\%$ & $\mathrm{n}$ & $\%$ & & & & $\mathrm{n}$ & $\%$ & $\mathrm{n}$ & $\%$ & & & \\
\hline Family structure & & & & & 0.092 & 0.955 & 0.007 & & & & & 0.060 & 0.970 & 0.009 \\
\hline $\begin{array}{l}\text { Living with none of } \\
\text { their parents }\end{array}$ & $14 \mathrm{a}$ & 1.7 & $18 \mathrm{a}$ & 1.9 & & & & $6 a$ & 2.3 & $9 \mathrm{a}$ & 2.1 & & & \\
\hline Monoparental family & $212_{\mathrm{a}}$ & 26 & $246_{a}$ & 26.1 & & & & $67 \mathrm{a}$ & 25.6 & $110_{\mathrm{a}}$ & 25.5 & & & \\
\hline $\begin{array}{l}\text { Living with both } \\
\text { parents }\end{array}$ & $588_{a}$ & 72.3 & $678_{\mathrm{a}}$ & 72 & & & & $189_{\mathrm{a}}$ & 72.1 & $318_{\mathrm{a}}$ & 72.8 & & & \\
\hline $\begin{array}{l}\text { Family with gambling } \\
\text { problems }\end{array}$ & $19 \mathrm{a}$ & 2.3 & 22 a & 2.3 & $<0.001$ & 1.000 & $<0.001$ & $6 a$ & 2.3 & $14_{a}$ & 3.2 & 0.223 & 0.637 & 0.027 \\
\hline $\begin{array}{l}\text { Most frequent academic } \\
\text { mark }^{\mathrm{a}}\end{array}$ & & & & & 30.654 & $<0.001$ & 0.137 & & & & & 12.959 & 0.005 & 0.142 \\
\hline $\begin{array}{l}\text { Failing grade (from } \mathrm{F} \\
\text { to } \mathrm{D}+\text { ) }\end{array}$ & $96 \mathrm{a}$ & 12.8 & 142 a & 16.1 & & & & $32_{\mathrm{a}}$ & 13.2 & $68 \mathrm{a}$ & 16.8 & & & \\
\hline Good (from $C-$ to $C+$ ) & $250_{\mathrm{b}}$ & 33.2 & 382 a & 43.2 & & & & $78_{b}$ & 32.2 & $173_{\mathrm{a}}$ & 42.7 & & & \\
\hline $\begin{array}{l}\text { Notable (from B - to } \\
\mathrm{B}+\text { ) }\end{array}$ & $302_{b}$ & 40.2 & $283 a$ & 32 & & & & $97_{b}$ & 40.1 & $128_{\mathrm{a}}$ & 31.6 & & & \\
\hline $\begin{array}{l}\text { Outstanding ( } \mathrm{A} \text { and } \\
\mathrm{A}+\text { ) }\end{array}$ & $104_{b}$ & 13.8 & 77 a & 8.7 & & & & $35_{\mathrm{b}}$ & 14.5 & $36_{\mathrm{a}}$ & 8.9 & & & \\
\hline Weekly allowance & & & & & 7.722 & 0.021 & 0.066 & & & & & 3.229 & 0.199 & 0.068 \\
\hline $0 €-20 €$ & $744_{b}$ & 91.4 & 824 a & 87.5 & & & & $229_{a}$ & 87.4 & $363_{\mathrm{a}}$ & 83.1 & & & \\
\hline $21 €-40 €$ & $56_{a}$ & 6.9 & $88 \mathrm{a}$ & 9.3 & & & & $23_{\mathrm{a}}$ & 8.8 & $58_{\mathrm{a}}$ & 13.3 & & & \\
\hline $41 €$ & $14 \mathrm{a}$ & 1.7 & 30 & 3.2 & & & & $10_{\mathrm{a}}$ & 3.8 & $16_{\mathrm{a}}$ & 3.7 & & & \\
\hline
\end{tabular}

Note. Subscripts indicate between-group differences. Groups with the same subscript did not differ significantly from each other.

${ }^{\text {a }} n=1636$ (left panel) and 647 (right panel) participants due to technical problems in the data collection. 
Table 2

Predictors of gambling severity by gender.

\begin{tabular}{|c|c|c|c|c|}
\hline & \multicolumn{2}{|c|}{ Female gamblers $(n=262)$} & \multicolumn{2}{|c|}{ Male gamblers $(n=437)$} \\
\hline & $\beta$ & $95 \% \mathrm{CI}$ & $\beta$ & $95 \% \mathrm{CI}$ \\
\hline SS & - & - & -0.099 & $-0.109-0.001$ \\
\hline Imp & $0.145^{*}$ & $0.013-0.104$ & $0.126^{*}$ & $0.016-0.145$ \\
\hline $\begin{array}{c}\text { Enhancement } \\
\text { motive }\end{array}$ & - & - & $0.204^{* *}$ & $0.037-0.119$ \\
\hline Coping motive & 0.389 & $0.116-0.211$ & $0.314^{* *}$ & $0.112-0.224$ \\
\hline $\begin{array}{l}\text { Last year prevalence } \\
\text { of bingo }\end{array}$ & 0.128 & $0.040-0.711$ & $0.149 *$ & $0.290-1.162$ \\
\hline $\begin{array}{l}\text { Last year prevalence } \\
\text { of OCGs }\end{array}$ & $0.133^{*}$ & $0.225-2.971$ & $0.145^{*}$ & $0.448-1.930$ \\
\hline $\begin{array}{l}\text { Mode of access } \\
\text { (land-based vs. } \\
\text { mixed mode) }\end{array}$ & $0.139 *$ & $0.060-0.555$ & - & - \\
\hline
\end{tabular}

Note. $\mathrm{CI}=$ confidence interval; SS = Sensation seeking score in the Impulsive SensationSeeking Scale; Imp = Impulsivity score in the Impulsive Sensation-Seeking Scale; OCGs $=$ other casino games

${ }^{*} p<0.05$.

${ }^{* * *} p \leq 0.001$

The Gambling Motives Questionnaire (GMQ; Dechant \& Ellery, 2011) ( $\alpha=0.88$ ) was used. As there was no Spanish adaptation, this version was translated back into English by a professional translator. It includes three dimensions; enhancement (to increase positive emotions) ( $\alpha=0.85$ ), coping (to decrease negative emotions) ( $\alpha=0.87$ ), and social (to increase affiliation) motives ( $\alpha=0.79$ ).

The Spanish adaptation (Becoña, 1997) of the South Oaks Gambling Screen - Revised for Adolescents (Winters, Stinchfield, \& Fulkerson, 1993) was used to assess gambling severity within the last year. Gambling was defined as any game which involves betting on money. The scores provide three categories: non-problem gambler (score of 0 or 1 ), at-risk gambler (score of 2 or 3) and problem gambler (score of 4 or more). Internal consistency assessed by Cronbach's alpha $(\alpha)$ was 0.66 .

A Spanish adaption of the Impulsive Sensation-Seeking Scale ( $\alpha=0.82$ ) was used to assess preference for change and uncertainty (Fernández-Artamendi, Martínez-Loredo, Fernández-Hermida, \& Carballo-Crespo, 2016), and the tendency to act without thinking or planning. This scale provides a general score and two subscores: impulsivity (Imp) ( $\alpha=0.77)$ and impulsive sensation-seeking (SS) $(\alpha=0.74)$.

A delay discounting task was presented to assess impulsive choice. Participants decided on different choices, ranging from $€ 1000$ after a fixed delay, versus various amounts of money given immediately. This procedure showed good reliability in our sample $(\alpha=0.89)$. Delay discounting was calculated using logk and the area under the curve.

\subsection{Data analyses}

Bivariate analyses were performed to explore gender differences in risk factors for last year gambling and gambling patterns. Cramer's $V$ and Cohen's $d$ were calculated.

Two multiple regressions explored which variables (risk factors and gambling patterns) predicted gambling severity by gender. Given the low sample size of at-risk and problem gamblers, both categories were merged following previous studies (Desai \& Potenza, 2008; Potenza et al., 2011).

Variables reaching significance at $p<0.10$ in bivariate analyses were assessed for multicollinearity. Predictors of at-risk/problem gambling for males and females entered into the model were: 1) most frequent academic mark; 2) enhancement motive; 3) coping motive; 4) social motive; 5) last year prevalence of OCGs; 6) bingo; 7) poker; 8) sports-betting; 9) scratch-tickets; 10) mode of access; 11) Imp subscale; 12) SS subscale. Tolerance values were $>0.67$ and variance inflation factors (VIF) were also below the rule of 10, indicating absence of multicollinearity (Menard, 1995; Neter, Wasserman, \& Kutner, 1989).

Receiver Operating Characteristic (ROC) analyses were performed to compare the specificity and sensitivity of each significant predictor of at-risk/problem gambling within groups (i.e., male and female gamblers). Gambling severity was defined as the state variable $(0=$ nonproblem gambler, 1 = at-risk/problem gambler). Contrast variables were those showing significance in the multiple regression models by gender. The Youden Index approach (Perkins \& Schisterman, 2005) was used to establish the optimal cut-off in terms of sensitivity and specificity: $(\mathrm{Y})$ : $\mathrm{Y}=$ sensitivity + specificity -1 . All analyses were conducted using IBM SPSS Version 22.0.

\section{Results}

\subsection{Gender differences in problem gambling prevalence}

Among those reporting gambling in the previous year, 14.4\% (101 out of 699 gamblers) were considered at-risk/problem gamblers. Past year prevalence of at-risk/problem gambling was $11.16 \%$ for males, which was more than triple the rate for females $(3.29 \%),\left(\chi^{2}(1)\right.$ $=10,180, p=0.001, V=0.125$ ).

\subsection{Gender differences in risk factors for gambling}

Differences between male and female gamblers in the following risk factors were found: most frequent academic mark (see Table 1), the Imp $(t(645)=1.972, p=0.049, d=0.16)$ and SS subscales $(t(645)$ $=-2.963, p=0.003, d=0.25$ ). Males showed better academic marks and a lower Imp score. Females scored higher in SS. The next risk factors showed no significant differences by gender: weekly allowance (see Table 1), presence of relatives with problematic gambling (see Table 1), family structure (see Table 1), the score of Impulsive Sensation-Seeking scale $(t(645)=-0.605, p=0.546), \log k$ ( $t(645)$ $=0.031, p=976)$, and the area under the curve $(t(645)=-1.305$, $p=0.192$ ).

Table 2 shows regressions indicating variables associated with gambling severity by gender. Variables associated with being either an at-risk/problem male or female gambler were: Imp score, last year prevalence of bingo, and OCGs. Specific predictors for males were: enhancement and coping motives. Mixed-mode gambling was related to gambling severity in females.

\subsection{Gender differences in gambling patterns}

Males engaged in a greater number of gambling activities over the last year than females $(t(697)=2.063, p=0.039, d=0.16)$ and spent more time gambling per occasion $(t(697)=2.097, p=0.036$, $d=0.16)$. Age at gambling onset $(t(697)=0.682, p=0.495)$, number of games within their first year of gambling $(t(697)=1.118$, $p=0.264)$, and money spent per gambling occasion $(t(697)=1.274$, $p=0.203$ ) showed no statistically significant differences between genders. Males reported gambling more for enhancement $(t$ (639) $=4.553, p<0.001, d=0.34)$, coping $(t(613)=2.719, p=0.007$, $d=0.20)$ and social reasons $(t(613)=2.175, p=0.030, d=0.17$. Male gamblers were more likely to bet in land-based (exclusively) $\left(\chi^{2}(1)=13.685, p<0.001, V=0.15\right)$ and mixed-mode $\left(\chi^{2}(1)\right.$ $=9.736, p=0.002, V=0.13)$ venues. Last year prevalence of OCGs, bingo, poker, sports-betting, and scratch-tickets was higher for males than for females. Gambling activities by mode of access and gender is shown in Table 3.

\subsection{Receiver operating characteristic analyses}

For female gamblers, the Imp score and last year prevalence of bingo maximized the area under the ROC curve. For male gamblers, the best predictors were enhancement and coping motives (see Table 4). 
Table 3

Types of activity by gambling mode $(N=699)$.

\begin{tabular}{|c|c|c|c|c|c|c|c|}
\hline & \multicolumn{2}{|c|}{ Female gamblers $(n=262)$} & \multicolumn{2}{|c|}{ Male gamblers $(n=437)$} & \multirow[t]{2}{*}{$\chi^{2}$} & \multirow[t]{2}{*}{$p$} & \multirow[t]{2}{*}{ Cramer's V } \\
\hline & $\mathrm{N}$ & $\%$ & $\mathrm{~N}$ & $\%$ & & & \\
\hline Bingo $^{a}$ & 94 & 49 & 98 & 51 & 14.210 & $\leq 0.001^{* *}$ & 0.146 \\
\hline Land-based bingo & 92 & 49.5 & 94 & 50.5 & 14.834 & $\leq 0.001^{* *}$ & 0.149 \\
\hline Mixed-mode bingo & 1 & 33.3 & 2 & 66.7 & 0.000 & 0.999 & 0.006 \\
\hline Poker $^{\mathrm{a}}$ & 18 & 11.6 & 137 & 88.4 & 55.469 & $\leq 0.001^{* *}$ & 0.285 \\
\hline Land-based poker & 15 & 11.2 & 119 & 88.8 & 47.512 & $\leq 0.001^{* *}$ & 0.264 \\
\hline Mixed-mode poker & 2 & 11.8 & 15 & 88.2 & 3.857 & 0.050 & 0.084 \\
\hline $\mathrm{OCGs}^{\mathrm{a}}$ & 5 & 13.5 & 32 & 86.5 & 8.528 & $0.003^{*}$ & 0.117 \\
\hline Land-based OCGs & 4 & 12.9 & 27 & 87.1 & 7.301 & $0.007^{*}$ & 0.109 \\
\hline Mixed-mode OCGs & 1 & 16.7 & 5 & 83.3 & 0.402 & 0.526 & 0.040 \\
\hline Lottery $^{\mathrm{a}}$ & 118 & 39.2 & 183 & 60.8 & 0.545 & 0.460 & 0.031 \\
\hline Land-based lottery & 113 & 40.8 & 164 & 59.2 & 1.920 & 0.166 & 0.055 \\
\hline Mixed-mode lottery & 5 & 29.4 & 12 & 70.6 & 0.196 & 0.658 & 0.026 \\
\hline Sports betting ${ }^{\mathrm{a}}$ & 72 & 25.8 & 207 & 74.2 & 26.190 & $\leq 0.001^{* *}$ & 0.197 \\
\hline Land-based sports betting & 66 & 29.2 & 160 & 70.8 & 9.253 & 0.002 & 0.118 \\
\hline Mixed-mode sports betting & 3 & 11.1 & 24 & 88.9 & 7.205 & $0.007^{*}$ & 0.109 \\
\hline Scratch-tickets ${ }^{\mathrm{a}}$ & 115 & 44.4 & 144 & 55.6 & 7.944 & 0.005 & 0.110 \\
\hline Land-based scratch-tickets & 110 & 44.7 & 136 & 55.3 & 8.006 & 0.005 & 0.110 \\
\hline Mixed-mode scratch-tickets & 3 & 33.3 & 6 & 66.7 & 0.000 & 0.999 & 0.010 \\
\hline $\mathrm{EGMs}^{\mathrm{a}}$ & 43 & 44.3 & 54 & 55.7 & 1.927 & 0.165 & 0.057 \\
\hline Land-based EGMs & 42 & 45.2 & 51 & 54.8 & 2.335 & 0.127 & 0.062 \\
\hline Mixed-mode EGMs & 1 & 33.3 & 2 & 66.7 & 0.000 & 0.999 & 0.006 \\
\hline
\end{tabular}

Note. OCGs = other casino games; EGMs = electronic gambling machines.

${ }^{\text {a }}$ Gambling activity regardless mode of access.

${ }^{*} p<0.05$.

*** $p \leq 0.001$

\section{Discussion}

This study advances knowledge regarding gender differences in adolescent gambling. We highlight three findings: 1) the prevalence of at-risk/problem gambling was higher for males; 2) males showed a more severe gambling pattern profile; and 3) both genders shared impulsivity, last year prevalence of bingo, and OCGs as variables associated with higher gambling severity. Enhancement and coping motives were related to gambling severity among males, while mixed-mode gambling was related to gambling severity in females.

The percentage of males with at-risk/problem gambling is more than three times higher than in females, which is consistent with research conducted with adolescents (Ellebogen, \& J.L., \& Gupta, R., 2007). As masculinity is demonstrated in social contexts, gambling might enable males to showcase it by performing acts of skill and fearlessness in social situations (Wong, Zane, Saw, \& Chan, 2013). Gambling provides men the appropriate occasion to prove their bravery and betting skills while performing their traditional gender role.

Gender differences were found in gambling patterns. Similar to previous findings, men's gambling preferences differ from women's (Merkouris et al., 2016), with much of this research indicating that males prefer strategic gambling activities (Phillips \& Wilson, 2009).

In accordance with previous studies, high impulsivity (SecadesVilla, Martínez-Loredo, Grande-Gosende, \& Fernández-Hermida, 2016) and specific gambling activities, such as bingo and OCGs (Hing, Russell, Tolchard, \& Nower, 2016; Moubarac, Shead, \& Derevensky, 2010) were associated with higher gambling severity for both genders. As impulsive individuals tend to act without forethought regarding negative consequences, they may be more likely to involve in gambling due to their sensitivity to immediate rewards (Nower, Derevensky, \& Gupta, 2004). On the other hand, social perceptions of bingo as an innocuous activity leads to a more accepting attitude, hence increasing this behavior. OCGs predicted gambling problems. In Spain, gambling law (Law 13, 2011) establishes that individuals under 18 can neither bet on any activity nor enter casinos or gambling halls. This fact reflects that they are transgressing prohibitions.

Interestingly, we found specific risk factors for gambling by gender. Predictors of gambling severity in males were enhancement and coping motives. Both predictors showed adequate accuracy for the detection of at-risk/problem gambling among males, as shown by sensitivity and specificity indices. Males gamble for reasons other than social motives, such as to increase positive emotions (Stewart \& Zack, 2008) or to seek

Table 4

Receiver Operating Characteristic (ROC) analyses of gambling severity predictors by gender.

\begin{tabular}{|c|c|c|c|c|c|c|c|c|}
\hline & \multicolumn{4}{|c|}{ Female gamblers $(n=262)$} & \multicolumn{4}{|c|}{ Male gamblers $(n=437)$} \\
\hline & $\begin{array}{l}\text { Cutoff } \\
\text { point }^{\text {a }}\end{array}$ & $\begin{array}{l}\text { Area under the ROC } \\
\text { curve }\end{array}$ & Sensitivity (\%) & Specificity (\%) & $\begin{array}{l}\text { Cutoff } \\
\text { point }^{\text {a }}\end{array}$ & $\begin{array}{l}\text { Area under the ROC } \\
\text { curve }\end{array}$ & Sensitivity (\%) & Specificity (\%) \\
\hline Imp & 5 & 0.698 & 60.0 & 70.7 & 4 & 0.594 & 65.2 & 51.6 \\
\hline Enhancement motive & - & - & - & - & 6 & 0.705 & 60.3 & 72.1 \\
\hline Coping motive & - & - & - & - & 2 & 0.680 & 55.1 & 75.2 \\
\hline Last year prevalence of bingo & - & 0.613 & 56.5 & 66.1 & - & 0.582 & 35.9 & 80.5 \\
\hline Last year prevalence of OCGs & - & 0.561 & 13.0 & 99.2 & - & 0.565 & 17.9 & 95.0 \\
\hline $\begin{array}{l}\text { Mode of access (land-based vs. } \\
\text { mixed mode) }\end{array}$ & - & 0.570 & 17.4 & 96.5 & - & - & - & - \\
\hline
\end{tabular}

Note. $\operatorname{Imp}=$ Impulsivity score in Impulsive Sensation-Seeking Scale; OCGs = other casino games

${ }^{\text {a }}$ Data only provided for continuous measures. 
sensory stimuli (Grant \& Kim, 2002). Mixed-mode access was related with gambling severity in females. This gender-specific risk factor provided poor sensitivity but high specificity for the detection of atrisk/problem gambling. However, it is important to consider the categorical nature of this variable. In many screening/diagnostic situations, a decision based on a binary outcome can be difficult and impractical, because only two sensitivity and specificity indices are yielded (Park, Goo, \& Jo, 2004). As mixed-mode gamblers present higher gambling severity (Gainsbury, Russell, Blaszczynski, \& Hing, 2015), monitoring female bettors would prevent them from progressing into more severe gambling behavior.

Despite the ex-post-facto design limitations, strengths exist. The sample size was larger than the one recommended in power analyses. Assessment tools also covered a wide range of psychosocial constructs, thus contributing to a comprehensive understanding of gambling behavior. Lastly, the use of the Infrequency Scale ensured quality data. Future efforts need to consider the use of behavioral tasks such as the Gambling Purchase Task (Weinstock, Mulhauser, Oremus, \& D'Agostino, 2016). This tool demonstrates good discriminant validity while reducing face validity and social desirability.

\section{Conclusions}

This study highlights the importance of considering sociodemographic and personality factors by gender when designing preventive and treatment programs. As gambling prevention has been scarcely developed in Spain, it is expected that this study will promote the implementation of gender-sensitive prevention efforts. Health professionals should consider emotion-focused strategies when dealing with male adolescents (e.g., problem solving) (Moyal, Henik, \& Anholt, 2013). The fact that mixed-mode gambling predicted gambling problems in females indicates that underage adolescents have little difficulty in accessing gambling venues. Besides providing parents with information about control measures to avoid internet misuse (e.g., security passwords, parental control), strengthening regulatory measures in the gambling industry is a pressing need. Also, preventive campaigns to reduce public stigma and stereotyping (e.g., enhancing community contact with female problem gamblers) are highly advocated (Hing, Nuske, Gainsbury, \& Russell, 2016). Online interventions offer a further, anonymous, support that would encourage females to seek help and treatment for gambling problems by reducing self-perceived stigma (Gainsbury \& Blaszczynski, 2011). Lastly, regulations such as imposing fines on gaming operators that breach gambling law (e.g., allowing minors to participate in gambling activity), or better electronic verification of player identity (i.e., identification by electronic signature) might preclude the development of gambling problems.

\section{Conflict of interest}

The authors report no conflicts of interest.

\section{Funding}

The study was supported by a grant from the Council for Economy and Work (GRUPIN14-047) and by a predoctoral grant from the Spanish Ministry of Economy and Competitiveness (MINECO) (Ref. BES-2016-076663). Both funding sources played no role in the study design, data collection, or analysis of the results.

\section{Acknowledgments}

Authors acknowledge the educational authorities, the schools and students for study participation.

\section{References}

American Psychiatric Association (2013). In Fifth Edition (Ed.). Diagnostic and statistical manual of mental disorders. Washington, D.C.: American Psychiatric Association.

Becoña, E. (1997). Pathological gambling in Spanish children and adolescents: An emerging problem. Psychological Reports, 81, 275-287. http://dx.doi.org/10.2466/ pr0.1997.81.1.275.

Blaszczynski, A., \& Nower, L. (2002). A pathways model of problem and pathological gambling. Addiction, 97, 487-499. http://dx.doi.org/10.1046/j.1360-0443.2002. 00015.x.

Calado, F., Alexandre, J., \& Griffiths, M. D. (2017). Prevalence of adolescent problem gambling: A systematic review of recent research. Journal of Gambling Studies, 33, 397-424. http://dx.doi.org/10.1007/s10899-016-9627-5.

Castrén, S., Basnet, S., Salonen, A. H., Pankakoski, M., Ronkainen, J. E., Alho, H., \& Lahti, T. (2013). Factors associated with disordered gambling in Finland. Substance Abuse Treatment, Prevention, and Policy, 8(24), 1-10. http://dx.doi.org/10.1186/1747597X-8-24.

Dechant, K., \& Ellery, M. (2011). The effect of including a monetary motive item on the gambling motives questionnaire in a sample of moderate gamblers. Journal of Gambling Studies, 27, 331-344. http://dx.doi.org/10.1007/s10899-010-9197-x.

Desai, R. A., Maciejewski, P. K., Pantalon, M. V., \& Potenza, M. N. (2005). Gender differences in adolescent gambling. Annals of Clinical Psychiatry, 17, 249-258. http://dx. doi.org/10.1080/10401230500295636.

Desai, R. A., \& Potenza, M. N. (2008). Gender differences in the associations between past-year gambling problems and psychiatric disorders. Social Psychiatry and Psychiatric Epidemiology, 43, 173-183. http://dx.doi.org/10.1007/s00127-007 0283-z.

Donati, M. A., Chiesi, F., \& Primi, C. (2013). A model to explain at-risk/problem gambling among male and female adolescents: Gender similarities and differences. Journal of Adolescence, 36, 129-137. http://dx.doi.org/10.1016/j.adolescence.2012.10.001.

Edgren, R., Castren, S., Jokela, M., \& Salonen, A. H. (2016). At-risk and problem gambling among Finnish youth: The examination of risky alcohol consumption, tobacco smoking, mental health and loneliness as gender-specific correlates. Nordic Studies on Alcohol and Drugs, 33, 61-80. http://dx.doi.org/10.1515/nsad-2016-0005.

Ellebogen, D., \& J.L., \& Gupta, R. (2007). Gender differences among adolescents with gambling-related problems. Journal of Gambling Studies, 23, 133-143. http://dx.doi. org/10.1007/s10899-006-9048-y.

Fernández-Artamendi, S., Martínez-Loredo, V., Fernández-Hermida, J. R, \& CarballoCrespo, J. L. (2016). The Impulsive Sensation Seeking (ImpSS): Psychometric properties and predictive validity regarding substance use with Spanish adolescents. Personality and Individual Differences, 90, 163-168. http://dx.doi.org/10.1016/j.paid. 2015.11.003.

Fonseca-Pedrero, E., Paino, M., Lemos-Giráldez, S., \& Muñiz, J. (2008). Construction and validation of the Oviedo Infrequency Scale in Spanish adolescents. Unpublished doctoral dissertationOviedo, Spain: Univerisity of Oviedo.

Gainsbury, S., \& Blaszczynski, A. (2011). A systematic review of internet-based therapy for the treatment of addictions. Clinical Psychology Review, 31, 490-498. http://dx. doi.org/10.1016/j.cpr.2010.11.007.

Gainsbury, S. M., Russell, A., Blaszczynski, A., \& Hing, N. (2015). The interaction between gambling activities and modes of access: A comparison of internet-only, land-based only, and mixed-mode gamblers. Addictive Behaviors, 41, 34-40. http://dx.doi.org/ 10.1016/j.addbeh.2014.09.023.

González-Ortega, I., Echeburúa, E., Corral, P., Polo-López, R., \& Alberich, S. (2013). Predictors of pathological gambling severity taking gender differences into account. European Addiction Research, 19, 146-154. http://dx.doi.org/10.1159/000342311.

González-Roz, A., Fernández-Hermida, J. R., Weidberg, S., Martínez-Loredo, V., \& Secades-Villa, R. (2016). Prevalence of problem gambling among adolescents: A comparison across modes of access, gambling activities, and levels of severity. Journal of Gambling Studies, 33, 371-382. http://dx.doi.org/10.1007/s10899-016-9652-4.

Grant, J. E., \& Kim, S. W. (2002). Gender differences in pathological gamblers seeking medication treatment. Comprehensive Psychiatry, 43, 56-62. http://dx.doi.org/10. 1053/comp.2002.29857.

Griffiths, M. (2005). A 'components' model of addiction within a biopsychosocial framework. Journal of Substance Use, 10, 191-197. http://dx.doi.org/10.1080/ 14659890500114359.

Hing, N., Nuske, E., Gainsbury, S. M., \& Russell, A. M. T. (2016). Perceived stigma and self-stigma of problem gambling: Perspectives of people with gambling problems. International Gambling Studies, 16, 31-48. http://dx.doi.org/10.1080/14459795. 2015.1092566.

Hing, N., Russell, A., Tolchard, B., \& Nower, L. (2016). Risk factors for gambling problems: An analysis by gender. Journal of Gambling Studies, 32, 511-534. http://dx.doi. org/10.1007/s10899-015-9548-8.

Kaminer, Y., Burleson, J. A., \& Jadamec, A. (2002). Gambling behavior in adolescent substance abuse. Substance Abuse, 23, 191-198. http://dx.doi.org/10.1080/ 08897070209511489.

Law 13/2011, May 27th, of gambling regulation, Boletín Oficial del Estado (BOE). May, 28th 2011.

Mayr, S., Erdfelder, E., Buchner, A., \& Faul, F. (2007). A short tutorial of GPower. Tutorials in quantitative methods for psychology, 3, 51-59. Retrieved from https://doaj. org/.

Menard, S. (1995). Applied logistic regression analysis: Stage university series on quantitative applications in the social sciences. Thousand Oaks, CA: SAGE Publications.

Merkouris, S. S., Thomas, A. C., Shandley, K. A., Rodda, S. N., Oldenhof, E., \& Dowling, N. A. (2016). An update on gender differences in the characteristics associated with problem gambling: A systematic review. Current Addiction Reports, 3, 254-267. 
http://dx.doi.org/10.1007/s40429-016-0106-y.

Moubarac, J. C., Shead, N. W., \& Derevensky, J. L. (2010). Bingo playing and problem gambling: A review of our current knowledge. Journal of Gambling Issues, 24, 164-184. http://dx.doi.org/10.4309/jgi.2010.24.10.

Moyal, N., Henik, A., \& Anholt, G. E. (2013). Cognitive strategies to regulate emotions-Current evidence and future directions. Frontiers in Psychology, 4, 1019. http://dx.doi.org/10.3389/fpsyg.2013.01019.

Neter, J., Wasserman, W., \& Kutner, M. H. (1989). Applied linear regression models. Homewood, IL: Irwin.

Nigro, G., Cosenza, M., \& Ciccarelli, M. (2017). The blurred future of adolescent gamblers: Impulsivity, time horizon, and emotional distress. Frontiers in Psychology, 8, 486. http://dx.doi.org/10.3389/fpsyg.2017.00486.

Nower, L., Derevensky, J. L., \& Gupta, R. (2004). The relationship of impulsivity, sensation seeking, coping, and substance use in youth gamblers. Psychology of Addictive Behaviors, 18, 49-55. http://dx.doi.org/10.1037/0893-164x.18.1.49.

Park, S. H., Goo, J. M., \& Jo, C. H. (2004). Receiver operating characteristic (ROC) curve: Practical review for radiologists. Korean Journal of Radiology, 5, 11-18. http://dx.doi. org/10.3348/kjr.2004.5.1.11.

Pérez Fuentes, M. D., Molero Jurado, M. D., Carrión Martínez, J. J., Mercader Rubio, I., \& Gázquez, J. J. (2016). Sensation-seeking and impulsivity as predictors of reactive and proactive aggression in adolescents. Frontiers in Psychology, 7(1447), http://dx.doi. org/10.3389/fpsyg.2016.01447.

Perkins, N. J., \& Schisterman, E. F. (2005). The Youden index and the optimal cut-point corrected for measurement error. Biometrial Journal, 47, 428-441. Retrieved from http://onlinelibrary.wiley.com/journal/10.1002/((ISSN)1521-4036) .

Petry, N. M., Stinson, F. S., \& Grant, B. F. (2005). Comorbidity of DSM-IV pathological gambling and other psychiatric disorders: Results from the national epidemiologic survey on alcohol and related conditions. The Journal of Clinical Psychiatry, 66, 564-574. http://dx.doi.org/10.4088/JCP.v66n0504.

Phillips, D. K., \& Wilson, V. A. (2009). Gambling and gender: Men and women at play. New York, NY: Peter Lang.

Potenza, M. N., Wareham, J. D., Steinberg, M. A., Rugle, L., Cavallo, D. A., Krishnan-
Sarin, S., \& Desai, R. A. (2011). Correlates of at-risk/problem internet gambling in adolescents. Journal of the American Academy of Child and Adolescent Psychiatry, 50(150-159), e153. http://dx.doi.org/10.1016/j.jaac.2010.11.006.

Sapienza, P., Zingales, L., \& Maestripieri, D. (2009). Gender differences in financial risk aversion and career choices are affected by testosterone. Proceedings of the National Academy of Sciences of the United States of America. 106. Proceedings of the National Academy of Sciences of the United States of America (pp. 15268-15273). . http://dx. doi. org/10.1073/pnas.0907352106.

Secades-Villa, R., Martínez-Loredo, V., Grande-Gosende, A., \& Fernández-Hermida, J. R. (2016). The relationship between impulsivity and problem gambling in adolescence. Frontiers in Psychology, 7, 1-7. http://dx.doi.org/10.3389/fpsyg.2016.01931.

Stanton, S. J., Liening, S. H., \& Schultheiss, O. C. (2011). Testosterone is positively associated with risk taking in the iowa gambling task. Hormones and Behavior, 59, 252-256. http://dx.doi.org/10.1016/j.yhbeh.2010.12.003.

Stewart, S. H., \& Zack, M. (2008). Development and psychometric evaluation of a threedimensional gambling motives questionnaire. Addiction, 103, 1110-1117. http://dx. doi.org/10.1111/j.1360-0443.2008.02235.x.

Stinchfield, R. (2000). Gambling and correlates of gambling among Minnesota public school students. Journal of Gambling Studies, 16, 153-173. http://dx.doi.org/10. 1023/A:1009428913972.

Topf, J. L., Yip, S. W., \& Potenza, M. N. (2009). Pathological gambling: Biological and clinical considerations. Journal of Addiction Medicine, 3, 111-119. http://dx.doi.org/ 10.1097/ADM.0b013e31819b7bff.

Weinstock, J., Mulhauser, K., Oremus, E. G., \& D'Agostino, A. R. (2016). Demand for gambling: Development and assessment of a gambling purchase task. International Gambling Studies, 16, 316-327. http://dx.doi.org/10.1080/14459795.2016.1182570.

Winters, K. C., Stinchfield, R., \& Fulkerson, J. (1993). Toward the development of an adolescent gambling problem severity scale. Journal of Gambling Studies, 9, 371-386. http://dx.doi.org/10.1007/BF01019925.

Wong, G., Zane, N., Saw, A., \& Chan, A. K. (2013). Examining gender differences for gambling engagement and gambling problems among emerging adults. Journal of Gambling Studies, 29, 171-189. http://dx.doi.org/10.1007/s10899-012-9305-1. 